Chapter 9

\title{
ENGAGING FARMERS AND UNDERSTANDING THEIR BEHAVIOUR TO DEVELOP EFFECTIVE DETERRENTS TO CROP DAMAGE BY WiLDLIFE
}

\author{
Graham E. Wallace and Catherine M. Hill
}

The interests of humans and wildlife frequently conflict wherever they coexist (see Conover 2002; Madden 2004; Thirgood, Woodroffe and Rabinowitz 2005; Young et al. 2005). Consequently, understanding and addressing these 'conflicts' is a key management issue for wildlife conservation (Messmer 2000; Paterson and Wallis 2005; Woodroffe, Thirgood and Rabinowitz 2005; Dickman 2010). Perceptions of interactions between humans and wildlife typically reflect the extent to which individuals live with wildlife (Newmark et al. 1993; Rao and McGowan 2002; Altrichter 2006) and reconciling perspectives usually involves meshing disparate goals (Adams 1998; Abbot et al. 2001; Hutton and Leader-Williams 2003; Baker et al. 2013). Land use and access to resources are often central to humanwildlife interactions (see Blomley 2000; Kagiri 2002; Mukherjee and Borad 2004), particularly in many rural areas of Africa where increasing human populations depend on limited land and decreasing forest resources for livelihoods (Kepe, Cousins and Turner 2001; Bush et al. 2004; Plumptre et al. 2004; Toutain, De Visscher and Dulien 2004). Resource competition between humans and wildlife can be prevalent where human communities relying on agriculture for food security and income adjoin forest reserves that provide essential habitat for wildlife (Hill 1997; Naughton-Treves 1997; Tungittiplakorn and Dearden 2002; Knickerbocker and Waithaka 2005). Crops near forest may be a predictable and accessible source of nutrition for wildlife, and therefore many species forage on them. 1 This can result in extensive ongoing damage to crops, with adverse impacts on farmer livelihood (Nyhus, Tilson and Sumianto 2000; Hill 2004; Chiyo et al. 2005; Rode et al. 2006). 
Animals have probably entered farmers' fields to consume crops for centuries, but interest in assessing the impacts of this behaviour is relatively recent (Hill, Osborn and Plumptre 2002). Many accounts have approached crop damage by wildlife from a conservation perspective, focusing particularly on its implications for wildlife (Horrocks and Baulu 1988; Plumptre and Reynolds 1994; Hill 2002b; Choudhury 2004; Sitati and Walpole 2006). However, because living closely with wildlife often affects humans adversely it is now widely acknowledged that human perspectives must be taken into account to not only mitigate crop losses and associated livelihood impacts but also promote conservation (Soto, Munthali and Breen 2001; Conover 2002; Hill 2002a; Sitati and Walpole 2006). This includes addressing the direct and opportunity costs of wildlife crop damage for farmers and their communities (see Naughton-Treves 1997; CARE et al. 2003; Hill 2005; Priston and McLennan 2013). While these communities are often sympathetic to conservation goals, the conflicts and costs generated by crop damage can reduce tolerance of wildlife and undermine management plans (Infield 1988; Strum 1994; Happold 1995; Lee and Priston 2005; Baker et al. 2013). Hence it is critical to work in partnership with these stakeholders when developing and implementing strategies to mitigate crop losses and associated conflicts (Osborn and Hill 2005; Sitati, Walpole and Leader-Williams 2005; Graham and Ochieng 2008; Redpath et al. 2013). Levels of crop damage, costs to replace lost food and farmers' investments in time or resources to protect their crops are measures of the impact of crop damage on livelihoods (Colfer, Wadley and Venkateswarlu 1999; Hill, Osborn and Plumptre 2002; Bush et al. 2004; MacKenzie and Ahabyona 2012). Although the threshold levels of loss that undermine farmer livelihood security probably vary across time and sites, relatively minor crop loss can adversely affect subsistence households in developing countries because farmers often lack savings, crop surpluses or alternative sources of income to absorb and offset losses (Barbier 1987; Van Huis and Meerman 1997; Bush et al. 2004; Hill 2004).

It should be noted that while much of the existing literature on crop damage by wildlife uses the term 'crop-raiding', we avoid using it here. As discussed elsewhere, terms such as 'raid', 'crop-raiding' 
and 'crop-raider' imply an unauthorised, malicious or harmful attack on farmers' property, with negative connotations that do little to mitigate conflict (see Webber 2006; Peterson et al. 2010; Hill 2015).

To manage crop damage by wildlife it is essential to have an accurate and comprehensive account of crop-foraging activity and impacts, which includes understanding farmers' perceptions and behaviour, the behavioural ecology of the species concerned and patterns and parameters of crop-foraging events. Mitigation strategies should not only deliver reduced crop loss for farmers but also lessen the associated social costs of these events (Gillingham and Lee 2003; Hill 2005; Webber 2006) and increase tolerance of wildlife (Naughton-Treves 1998). It is also possible that crop damage is only one aspect or focus of wider farmer frustrations (Hill 2004; Madden 2004). It is therefore necessary to balance farmers' perceptions with what is observed to occur on farms, because disparity can compromise mitigation efforts; there will be little value in addressing A if the real cause or issue is B (see Hill, Osborn and Plumptre 2002; Osborn and Hill 2005).

Actively involving all stakeholders throughout each stage of the process of 'conflict' mitigation (1) improves understanding of perceptions and any differing perspectives, (2) ensures that aims, actions and outcomes are likely to be relevant across all stakeholders and aligned with their interests or concerns, (3) ensures interventions are locally appropriate and consistent with local norms and customs, (4) increases ownership of core issues and the need to find solutions and (5) maximizes the probability that strategies will be effective, and hence used or adapted, over the long term (Strum 1986; Kapila and Lyon 1994; Gillingham and Lee 1999; Hackel 1999; Miller and McGee 2001; Hill, Osborn and Plumptre 2002; Armitage 2003; Osborn and Parker 2003; Riley et al. 2003; Chase, Decker and Lauber 2004; Osborn and Hill 2005; Sitati and Walpole 2006; Webber, Hill and Reynolds 2007). Although many techniques traditionally employed by farmers to protect their crops from wildlife are not legally sanctioned, it is unreasonable and impractical to expect farmers to stop using methods they perceive to be effective without providing access to alternatives aligned with conservation goals (Hill, Osborn and Plumptre 2002). 
Central to reducing crop losses due to wildlife foraging activities is ensuring farmers have access to a range of effective and affordable tools to protect their crops (Hill, Osborn and Plumptre 2002; Osborn and Hill 2005; Hill and Wallace 2012). To develop these tools it is necessary to measure and understand animal foraging activity within an area, including a thorough record of the frequency of crop-feeding events, which species feed on crops and which crops are damaged (Hygnstrom, Timm and Larson 1994; Conover 2002). It is also essential to understand when and where crop-foraging events occur, under what conditions they occur, the amount of crop loss that occurs and which parameters of crop-foraging events determine crop loss (Wallace and Hill 2012). Behavioural information about crop-foraging species can indicate how they respond or adapt to human activity and crop-protection efforts (Barnes 1996; Boydston et al. 2003; Beale and Monaghan 2004; Fuentes, Southern and Suaryana 2005). This information can then be used to design deterrents to crop foraging that address specific attributes of foraging dynamics as well as animal species characteristics (Conover 2002; Wallace 2010).

Deterrents are usually grouped according to how they operate or are used (for example, active, passive, physical, tactical, vigilant, noise, sensory, barrier, alarm, repellent, lethal); in practice, most can be assigned to more than one group. Some methods, such as burning pepper dung to deter elephants (Osborn and Parker 2002a), or hanging monofilament lines and flags to deter ducks (Lane and Higuchi 1998), are relatively species-specific, while methods such as chasing, guarding and using traps or wire fences may deter a broad range of species. Lethal removal of animals can occur through hunting or use of traps, snares, weapons, baits or poison; in many areas these activities are probably the most 'traditional' of farmers' responses to wildlife foraging on crops (Hill 1997; Naughton-Treves 2001; Hill 2004).

Methods to protect crops are most likely to be used, adapted over time and perceived to be effective if supported by farmers (Osborn and Parker 2003; Sitati and Walpole 2006). Farmers' capacity to protect their crops may involve compromises between desirable techniques and those that are feasible and affordable. These limitations can lead to frustrations for farmers that fuel 'conflicts' around wildlife rhetoric, especially when crop damage is persistent and involves considerable costs. Because farmers 
typically approach crop protection with few resources it is critical to understand wildlife foraging behaviour in order to maximize deterrent utility. The utility of an effective deterrent may be derived quantitatively by comparing crop-loss savings with costs of the deterrent over time. However, deterrent utility is also qualitative and will be influenced by a farmer's perceptions and expectations about the effort and opportunity costs to implement, use and maintain the technique (Conover 2002; Osborn and Parker 2003; Forthman, Strum and Muchemi 2005; Osborn and Hill 2005; Sitati and Walpole 2006; Graham and Ochieng 2008).

Farmers' attitudes and perceptions about crop damage and wildlife species causing this damage should be assessed when developing deterrent strategies, to ensure actions and anticipated outcomes are likely to address concerns (Pirta, Gadgil and Kharshikar 1997; Gillingham and Lee 1999; Osborn and Hill 2005; WWF 2005). Consultation with farmers and other key local people is imperative to agreeing plans and goals, and also staying informed about the steps, limitations, local resources or timeframes to take into account (Strum 1986; Osborn and Parker 2003; Hill 2004). Interventions should fit with local social norms, customs, or constraints, gender- or age-specific roles and labour availability over agricultural seasons (see Hill, Osborn and Plumptre 2002). Involving farmers actively in planning deterrent strategies often increases their ownership of techniques and commitment to finding solutions, reducing dependence on 'outsiders' (Hill, Osborn and Plumptre 2002; Osborn and Parker 2002a; Sitati, Walpole and LeaderWilliams 2005; Graham and Ochieng 2008). There may be fewer calls for compensation for damage by wildlife when deterrents are developed with farmers and provide ongoing savings in crop loss, which is important because compensation does not reduce the incidence of crop damage, diminishes incentives to protect crops and can lead to deliberate crop damage and/or exaggerated claims (Hoare 1995; Rollins and Briggs 1996; Plumptre 2002; Bulte and Rondeau 2005; Sitati and Walpole 2006).

A deterrent used frequently, widely or over long periods of time is not necessarily effective; rather, it could be used because farmers lack, or perceive they lack, feasible alternatives. This is often the case for small-scale farmers, where traditional deterrents may be labour-intensive, inefficient and 
ineffective but the only options a farmer can afford and access with available resources (Hill, Osborn and Plumptre 2002). However, traditional deterrents such as basic fences, guarding and vigilance, or throwing objects, chasing and even culling animals feeding on crops may be appropriate in many contexts, especially when used systematically (see Osborn 2002). Traditional deterrents should be considered first when planning to address crop losses to animal foraging: techniques that farmers are familiar with are likely to be locally acceptable and readily modified to suit different circumstances, as well as easier to build on when greater efficiencies are required (Hill, Osborn and Plumptre 2002; Osborn and Hill 2005). The costs of deterrents and availability of resources must be factored into crop-protection strategies to ensure they retain value (i.e. are effective, efficient and affordable) for individual farmers over time.

In this chapter we describe the process of developing, implementing and evaluating a series of crop-protection tools in partnership with subsistence farmers in north-western Uganda. We reflect on the practicalities, benefits, potential costs and effectiveness of such an approach, and outline intervention considerations for future projects designing and implementing methods to deter crop-raiding.2

\section{Case Study: Partnering with Farmers in Uganda to Deter Crop Damage by Wildlife}

\section{Background}

The study took place in six villages (Nyakafunjo, Nyabyeya 2, Kyempunu, Fundudolo, Marram, Panyana) around the southern edge of the Budongo Forest Reserve, Masindi District, Uganda (figure 9.1). Based on national census and population growth figures, there were approximately 5,300 people living in the study area on project commencement in 2006. Up to 70 per cent of people within the study area rely on agriculture for livelihood and subsistence farming predominates (Hill 1997; Webber 2006); consequently, any activity or event undermining crop yields will have potentially widespread impact on local food security and livelihoods. These can include stochastic weather events (such as onset of seasonal rain, storms, drought and lightning strikes igniting fires), crop production and market prices, seed quality, seed supply, soil fertility, crop damage by insects or disease and crop consumption by wildlife (Tweheyo, Hill 
and Obua 2005). Many local farmers perceive that wildlife foraging on crops is the problem with greatest risk experienced on their farm (Webber and Hill 2014).

$<$ Insert Figure 9.1 here $>$

Figure 9.1. Map showing the location of Budongo Forest Reserve in north-western Uganda.

The research was conducted in accordance with institutional ethics requirements and clearance, established guidelines for ethical social and primate research and with the consent and support of village councils and participating farmers. Permissions for the research were granted by the Uganda National Council for Science and Technology, Uganda Wildlife Authority, and National Forestry Authority, Uganda. The research occurred in the same area as earlier investigations of crop damage and farmerwildlife interactions by Catherine Hill and Amanda Webber. Working in the same villages, and with some of the same farmers as Hill and Webber, provided context and continuity for the study. Additionally, the goodwill generated in local communities by the previous research helped to ensure local support for the project. This positive foundation at commencement of the study meant that introductions and logistics within study villages were considerably more straightforward than they otherwise might have been. Chairpersons of each study village were provided with details of the proposed project, objectives, methods, and timetable and then requested to permit the research to be conducted in the village and also allow GW to approach individual farmers for recruitment. Permissions were granted in all cases. Farms were identified for inclusion in the study after evaluating their extent of view of forest edges, history of crop damage by wildlife and planned crops (Hill 2000; Webber 2006); thirteen farms were selected and each was located at the forest edge (see Wallace and Hill 2012). Predominant crops on study farms, as well as across the study area, were maize (Zea mays), beans (Phaseolus vulgaris), sorghum (Sorghum bicolor), cassava (Manihot esculenta and Manihot palmata), millet (Eleusine coracana) and bananas 
(Musa spp.). Key project stakeholders were farmers and their families, others supported by farming, local communities, village councils and government agencies; other interested groups were a local association of sugar cane farmers as well as non-governmental organizations.

\section{Project Design}

The original research was designed to develop, implement and evaluate a set of effective and locally acceptable crop-protection tools to reduce the impact of wildlife on subsistence livelihoods in farming areas adjacent to forest habitat (Wallace and Hill 2012). Including local farmers throughout all stages of the project was of primary importance and this is reflected in the research design (Hill and Wallace 2012). An interview averaging forty-five minutes in duration was conducted with each study farmer (1) prior to commencing systematic on-farm observations, (2) at the end of Year One and (3) at the end of Year Two. Three 3-hour focus-group sessions, as well as an end-of-study results and training workshop, were also conducted with farmers and village chairpersons. Each focus group provided a formalized opportunity for farmers to contribute to developing deterrents and reflect on the process.

The aim in Year One was to acquire baseline information about farmer and wildlife behaviour around crop-foraging events. All study farmers were encouraged to carry out their usual farming practices and patterns of activity, including responses to animals foraging on crops, vigilance and deterrent behaviour. A crop-raiding event (CRE) 3 was defined to occur when one or more individuals of an animal species entered a farm (i.e. crossed a farm boundary), interacted with one or more crop stems and left the farm (Wallace 2010). The CRE commenced when the first individual entered the farm and ended when the last individual exited. Baseline data on the behaviour of people and animals (wild and domestic) were systematically recorded to (1) identify species responsible for damaging crops, (2) establish the frequency and extent of crop-damage events, (3) examine farmer detection of and responses to animals on or around their farms and (4) explore animal responses to existing strategies for crop protection utilised by farmers. The results of these initial observations were fed back to farmers through individual discussions at the end 
of Year One, including a written summary of the key findings for their farm, as well as focus-group sessions prior to Year Two. Although it was originally intended to record crop-foraging events during the day and night, local logistics and the need to utilize artificial light sources to observe nocturnal species precluded data collection at night and the study focused on diurnal species. However, many farmers reported crop-foraging by nocturnal animals, mainly bush pigs (Potamochoerus porcus) and porcupines (Hystrix cristata), and some deterrents were developed to address this.

Focus-group sessions were conducted with farmers and village chairpersons prior to Year Two to explore options for deterrents, considerations when constructing and monitoring deterrents and prior experiences with crop-protection techniques. Each session was in a different village and farm to minimize travel distances for the participants. A broad range of ideas and options for deterrents were generated by farmers; most were uncomplicated and affordable, and could be readily implemented. Farmers were also positive about potential deterrent techniques suggested by the research team from analysis of cropforaging activity during Year One, and did not deem any proposed options unacceptable. The initial behavioural observation results, in conjunction with ideas generated by focus-group participants, were used to identify the primary aspects of farmer-animal interactions that could be manipulated to reduce crop damage by animals: these were improving farmer detection of animals entering farms and reducing wild animals' ability and/or willingness to enter crop fields.

In contrast, for Year Two the aim was to assess the efficacy of deterrents. Consequently, study farmers were encouraged to modify their crop-protection efforts or adopt new methods. This often involved farmers adjusting their behaviour according to the perceived benefits, demands or shortcomings of each deterrent implemented at their farm. Deterrents were tested on thirteen farms across the six study villages. Each of the farms had at least one boundary adjoining forest that provided natural habitat for primates and other wildlife; each of these boundaries comprised a farm-forest interface (FFI).

As agreed with farmers prior to onset of the research, researchers had an unobtrusive and passive role on farms, not responding to animals entering farms and also not disclosing wildlife presence or 
foraging activity to any people on farms. Study farmers also actively participated in data collection by reporting a broad range of details for each crop-damage event they detected (and usually responded to) when the research team was not observing at their farm. These damage events (referred to as reported CREs) were additional to those observed by the research team during systematic sampling (referred to as observed CREs). Information provided by farmers was compiled regularly and at least twice each week. As far as possible, parameters recorded for each reported CRE were the same as for observed CREs provided the event could be substantiated. Substantiation was via signs of wildlife, such as tracks or scat, and evidence of crop damage.

Farmers were advised before observational sampling commenced that all details about cropdamage events that occurred when researchers were not at their farm would be helpful and informative for the research. While farmers did not routinely describe crop damage in systematic terms, it became evident that they could recall accurately a broad range of crop-damage event parameters when guided about which were relevant, particularly those directly influencing the amount of stem damage sustained (Wallace 2010). Recall reliability was assessed regularly with each farmer by having them describe a CRE they had responded to during an observation session and then comparing the details recalled with researcher records. In each case the crop-damage event had occurred at least one day prior to recall assessment to simulate the average time interval between when damage by wildlife occurred and when the CRE was reported to the research team. Each farmer was able to recall the key parameters of the nominated CRE at almost 90 per cent concordance with researchers' records. Farmers could identify reliably each animal species, including primates, commonly occurring near their farm. Interestingly, farmers appeared to be interested mainly in recalling details of crop damage by wildlife, even though advised that damage to crops by domestic farm animals, such as pigs or goats, was equally important to the study. 


\section{Observing and Understanding the Linkages between Farmer and Wildlife Behaviour}

Primates were involved in 96 per cent of observed CREs by wildlife $(n=227)$, accounting for 99 per cent of crop stems damaged $(\mathrm{n}=4,168)$. Species observed damaging crops were olive baboons (Papio anubis), red-tailed monkeys (Cercopithecus ascanius schmidti), vervet monkeys (Chlorocebus aethiops), blue monkeys (Cercopithecus mitis stuhlmanni), chimpanzees (Pan troglodytes schweinfurthii) and black and white colobus monkeys (Colobus guereza occidentalis). Maize and beans were the crops foraged on most frequently across study farms (Wallace and Hill 2012).

Farmers' views of disturbance caused by primates and other wildlife, gauged from responses during semi-structured interviews, were very similar across the sample and broadly concurred with our independent observations summarized above. All farmers stated that primates cause more crop damage than other wildlife, although most added that bush pigs can damage crops extensively. Baboons were ranked by farmers as the worst animal for causing crop damage, bush pigs were ranked second, and monkeys other than baboons were ranked third. All farmers stated that maize was damaged most often and extensively by primates, followed by beans, bananas or millet.

Observations of farmer behaviour, monitoring of farms and discussions with farmers confirmed they use various, although not necessarily effective, methods (such as scarecrows, village bells, sporadic guarding, or vine fences) to protect crops but are aware of more potentially effective methods (including alarm systems, wire fences, and extensive guarding) they can feasibly access. It also became apparent that many farmers did not use crop-protection techniques to the extent they said they did. A striking example of variation between stated behaviour and observed behaviour was guarding activity. Discussions with farmers confirmed that they (and the research team) considered guarding to involve presence in crop fields near forest edges for extended periods of time or continuously, patrolling crop fields, vigilance and scanning for wildlife approaching or entering the farm and active responses if animals are detected; most farmers also considered this the ideal situation, which was sometimes not possible. 
Patterns of guarding described by farmers were markedly different to the patterns observed in Year One. Far from occurring throughout each day over the season, guarding comprised only 15.5 per cent of the farmer activity budget across all study farms (Wallace 2010), yet farmers remarked that if they did not 'guard well' (i.e. diligently) at the times they said they guarded then they would lose from one to three quarters of their crop stems to wildlife. Farmers linked amounts of loss directly to the extent and quality of guarding. Most farmers (76.9 per cent) reported guarding at their farm was organised, intensive (i.e. approached seriously and with a large time investment, often at the expense of other activities), involved all family members except infants, and occurred in shifts to ensure crops were always protected. When interviewed at the end of Year One, knowing they had been observed, 42 per cent of farmers stated they had guarded to a greater extent than in previous seasons while 58 per cent 'admitted' they had done little guarding over the season compared to the amount originally stated. Similarly, six of eight farmers who stated they guarded for most of each night probably did not do so. Although ten farmers claimed to light fires at night near a guard hut or the farm-forest edge to signal their presence to bush pigs, there were signs of fires at only two farms where some guarding at night probably occurred.

Overall, the extent of guarding that occurred at each study farm during Year One was probably too limited and sporadic to be effective for crop protection. In many instances, any value guarding had as a deterrent would have been compromised by poor quality of guarding behaviour.4 Very few individuals observed guarding were vigilant or patrolled fields for longer than one bout of approximately thirty to sixty minutes. Farmers appear to consider guarding as a sedentary rather than dynamic activity. Children were distracted regularly while guarding and were often observed to play instead, even occasionally breaking maize stems while playing.

Most guarding activity appeared to be carried out by adult women, which is common within subsistence farming communities (see Colfer, Wadley and Venkateswarlu 1999; Hill, Osborn and Plumptre 2002; Webber 2006). This could have reduced the time women allocated to household tasks and/or alternative sources of income; however, activity budgets confirmed it was not directly due to men 
allocating most of their time to working on-farm. At several study farms men were absent more than women and more likely to participate in logging or pit-sawing within the forest. Overall, the labour and/or opportunity costs of guarding (Naughton-Treves 1997; Hill, Osborn and Plumptre 2002; Gillingham and Lee 2003) were relatively low at study farms because guarding did not comprise a large proportion of farmers' time and did not occur at expense of work to grow food or generate income.

Using systematic observational techniques in partnership with study farmers made it possible to determine that they did relatively little to actively or passively protect their crops from wildlife, contrary to their claims, as also found by Liva Hansen (2003) about farmers in Sulawesi, Indonesia. Systematic observations also revealed that, in most cases, techniques of crop protection used by farmers (such as scarecrows, intermittent guarding, and vine fences) were ineffective, or only sporadically effective. Although this was probably partly due to inconsistent crop-protection behaviour, some farmers indicated they use these methods because they do not know what else to do to deter animals and affordable alternatives are lacking.

\section{Approach and Rationale when Developing Deterrents}

It was important that the deterrents introduced at study farms were easy for farmers to use, relatively or potentially affordable, used materials farmers could source locally, and required minimal maintenance in terms of effort and cost; otherwise the methods would be impractical and of little value for farmers. Within this context, however, the primary objectives for the research were to (1) determine which deterrent methods reduced crop-foraging, (2) assess how the deterrents operated, (3) establish why they were effective or ineffective and (4) gauge how useful the techniques could be for farmers. These aims meant that when alternative crops were trialled as deterrents such as ocimum, Ocimum

kilimandscharicum, and jatropha, Jatropha curcas, cash saleability or immediate profitability of the crop for a farmer was not the driving factor in deterrent evaluation. Because economic conditions and markets for crops will almost invariably fluctuate over time (Bigagambah 1996; Padulosi, Eyzaquirre and 
Hodgkin 1999), developing deterrents that were effective in terms of impacts on crop-foraging took precedence over short-term crop marketability. It was also anticipated that donor development and conservation agencies would be more likely to help farmers defray the costs of deterrents when efficacy was demonstrated and measurable.

Reduced crop loss was the main measure of deterrent value for farmers but they also identified long-term effectiveness as an important consideration when deciding to invest in a deterrent. Because farmers viewed deterrent value in terms of costs and benefits over time, it was possible to evaluate methods that used relatively long-lasting but more-expensive materials that a local farmer would need to plan to purchase from savings rather than access from the forest. It was important that forest resources were not essential to construct and/or operate the deterrents.

\section{Implementing, Monitoring and Evaluating Deterrents}

Baseline results were used to assess which deterrents would be (1) best evaluated and rigorously tested at each FFI and (2) of most benefit to individual farmers given the frequency and patterns of crop loss experienced. This information was used in conjunction with each farmer's preferences to allocate deterrents for evaluation. Farmers had input into which deterrents were trialled at their farm, and were able to veto any suggestions they disagreed with or did not consider practical. Ongoing consultation with farmers ensured each deterrent was introduced and monitored in partnership with them. It was agreed with farmers that it was not feasible to test all deterrents at each farm. Rather, it was acknowledged that the aim of the intervention stage of research was to determine which deterrent methods were effective, which were not effective, and why, and this would be best achieved by matching deterrents to specific FFIs.

Farmers were advised that deterrent techniques can differ in impact at different farms and also with different animal species. Therefore, their experiences of a deterrent might vary across the season as part of determining whether and how the technique worked, and whether it operated specifically or 
broadly. Because most study farmers knew each other and shared experiences, it was essential to advise them from the outset of Year Two that some might have better results than others from similar deterrents (as well as different deterrents) and this was an important aspect of deterrent evaluation. Otherwise, some might have been disappointed or disillusioned if they perceived they were not receiving the same benefits as others. Farmers were assured the results and information gained from testing each deterrent would be shared with all of them on project completion, and would therefore benefit each farmer in subsequent seasons. Farmers were also advised that it could be necessary to adjust or modify techniques over time because animals often habituate to deterrents and develop ways to bypass them. Primates are especially likely to do this due to their intelligence, behavioural flexibility, dexterity, cooperative capacity and social organization (Maples et al. 1976; Strum 1994; Hill, Osborn and Plumptre 2002; Forthman, Strum and Muchemi 2005; Osborn and Hill 2005).

An extensive range of tools, techniques and structures to deter crop-foraging wildlife were implemented at study farms in Year Two, including barbed-wire fences, mesh fences, rope fences, solar lights, trenches, vegetation barriers, chilli powder, nets, bells, systematic guarding, dogs, glasses for farmers, alternate locations and timing for crops and synchronization of crops. Some of the deterrents were used in combination (table 9.1). We could not guarantee outcomes for farmers, therefore all costs for materials and related expenses (including labour to transport materials to farms) were paid from project funds. Construction of deterrents was undertaken by the research team together with farmers. Although each farmer incurred effort costs in trialling a deterrent, project funding ensured any benefits accrued without monetary investment, allowing farmers to focus on deterrent utility and effectiveness. It is believed that being provided with deterrents did not bias farmers' use of any deterrents or perceptions about them (Heong and Escalada 1998; Bernard 2002). Farmers were assured deterrents could be removed at their request at any time, and would be removed on completion of the study unless they requested otherwise. 
Table 9.1. Deterrents trialled, their capacity to reduce crop damage by animals, animal species deterred and farmers' evaluations. Source: Adapted from Hill and Wallace (2012) and Hsiao et al. (2013).

\begin{tabular}{|c|c|c|c|}
\hline \multirow[t]{2}{*}{ Deterrent } & \multirow{2}{*}{$\begin{array}{l}\text { Capacity to reduce crop } \\
\text { damage }\end{array}$} & \multirow[t]{2}{*}{ Animal species deterred effectively } & \multirow{2}{*}{\begin{tabular}{|l|} 
Farmer evaluation \\
Benefits
\end{tabular}} \\
\hline & & & \\
\hline Paid guards & Yes. & Primates. & $\begin{array}{l}\text { Effective when systematic. Saves } \\
\text { farmer's time. }\end{array}$ \\
\hline Guard dogs & $\begin{array}{l}\text { No, except as a form of } \\
\text { alarm. }\end{array}$ & & Able to detect raiding animals. \\
\hline Barbed-wire fence & Yes. & $\begin{array}{l}\text { Bush pigs. Larger primates, } \\
\text { especially if linked with active } \\
\text { guarding or chasing. }\end{array}$ & $\begin{array}{l}\text { Effective and long-lasting. No need } \\
\text { for farmer to be present. }\end{array}$ \\
\hline Net fence with bells & Yes. & Primates, especially smaller species. & $\begin{array}{l}\text { Allows farmer to work away from } \\
\text { farm edges. }\end{array}$ \\
\hline Rope fence with bells & $\begin{array}{l}\text { No. Potentially, if } \\
\text { constructed to border all } \\
\text { fields. }\end{array}$ & & $\begin{array}{l}\text { Potentially useful alarm if borders } \\
\text { many crop fields. }\end{array}$ \\
\hline $\begin{array}{l}\text { Rope fence with chilli } \\
\text { powder }\end{array}$ & Yes. & Primates, especially smaller species. & $\begin{array}{l}\text { Effective and does not require farme } \\
\text { presence. }\end{array}$ \\
\hline Ocimum hedge & Yes, when used with wire & Primates. & Hardy, easily grown as a dense hedg \\
\hline
\end{tabular}




\begin{tabular}{|c|c|c|c|}
\hline & mesh fence. & & Potential cash crop. \\
\hline Jatropha hedge & Yes. & Primates. Bush pigs. & $\begin{array}{l}\text { Hardy, inexpensive, easy to propaga } \\
\text { and extend. Other household fuel } \\
\text { uses. }\end{array}$ \\
\hline Trench & No. & & Usually inexpensive. \\
\hline Alarms generally & Yes. & Primates. & $\begin{array}{l}\text { Alerts farmer before crops are } \\
\text { damaged. }\end{array}$ \\
\hline Solar lights & Yes. & Bush pigs. & $\begin{array}{l}\text { Effective and do not require fuel. } \\
\text { Other household uses out of crop } \\
\text { season. }\end{array}$ \\
\hline
\end{tabular}

Several deterrents at study farms improved farmer detection of CREs, namely paid guards, net fences with bells and alarms generally (see table 9.1 for a summary); further details are reported by Hill and Wallace (2012). Farmers may also have been more focused on being vigilant during Year Two because of deterrent-related activities. Farmers were aware of the Year One results prior to Year Two, which could have modified their vigilance in a manner similar to epistemic feedback noted in organizational behaviour research (Rollinson 2005; Buchanan and Huczynski 2010). Compared to Year One baseline values, several farmers were observed to modify their behaviour during Year Two as a result of deterrent implementation. In most cases farmers allocated less time to guarding because they perceived deterrents reduced the need to guard, even where it could have enhanced deterrent efficacy (for example, in conjunction with vegetation barriers). Farmers who decreased their guarding effort allocated more time to work and income activities such as weeding crops, brewing and pit-sawing. Although these 
shifts in activity were not anticipated, they provide insights about the potential opportunity costs of protecting crops.

Each farmer reported the deterrents trialled at their farm to be useful and effective, and all stated they gained benefits from the deterrents and would continue to use them. Accordingly, each farmer requested that deterrents remain in situ for ongoing use or extension. Farmers' favourable ratings for deterrents could have reflected an intent to please the research team and provide 'correct answers' (Morton-Williams 1993; Esterberg 2002; Randall and Koppenhaver 2004), especially because they were funded by the project, but it was evident they perceived the deterrents as valuable and responsible for reduced crop loss. From the farmers' perspective the deterrents mitigated crop losses to wildlife, and to a large extent this was probably achieved because farmers could 'buy in' via involvement at all stages of the intervention process. Many of the deterrents were still in use a year after the research was completed and numerous farmers not included in the original study had installed similar or modified versions of the trialled deterrents on their own farms (Hsiao et al. 2013).

Farmers rated deterrents on a cost-benefit basis. Although some deterrents (such as extensive barbed-wire fences, mesh fences, solar lights or full-time systematic guarding) were not readily affordable for many farmers, it was generally acknowledged that savings in crop losses and labour would usually offset costs over time. In addition, demonstrating and measuring the effectiveness of these and similar deterrents probably increased their suitability for support from conservation and development agencies (see O'Connell-Rodwell et al. 2000; Sitati, Walpole and Leader-Williams 2005). Deterrents such as jatropha, ocimum, and chilli were perceived as very cost effective because they can be readily grown by farmers and require minimal maintenance (table 9.1).

When interviewed at the end of Year Two, one farmer confirmed barbed-wire fences 'work very well for stopping bush pigs'; his family was 'very happy to have the fence' because he could get more sleep at night and they lost less maize than in other seasons. The farmer nominated additional sleep due to 
less guarding at night as a major benefit of the fence because he could then work on the farm for 'many more hours each day for most of the season'. As a result, it had not been necessary to pay people to help weed his crop fields, as required when he spent more time guarding at night. Additional time to work on the farm had also allowed his wife to spend more time on household tasks. The farmer envisaged the fence would require only minor maintenance for three to four years, and the barbed wire would outlast the posts due to termite damage. Although the cost of replacing the wire was viewed as a potential shortcoming of the fence, the farmer added he had 'many years to save the shillings' for this and the fence would 'help him to save more money' over future years (Wallace 2010).

Another farmer stated solar lights were 'powerful and could be seen from many farms away' and were 'very good for scaring or stopping bush pigs'. The farmer envisaged the lights would also be very useful as lighting in his house between growing seasons, saving him the cost of other fuels. He added that solar lights were easy to recharge and use, and flexible deterrents because they could be moved to other locations as required; however, because the lights were useful and conspicuous, the farmer felt they were at high risk of being stolen. The farmer ensured the lights were collected from the farm edge at dawn, recharged at his house each day, and many people in the village knew the lights were his property (Wallace 2010).

A farmer trialling chilli paste applied to a rope fence stated that chilli paste was 'easy to mix' and 'powerful', and key to the fence's effectiveness. The farmer added that almost one hour was required every three to four days to apply the paste to the fence, which was a small time investment relative to benefits. The farmer planned to maintain the fence, replace the sisal rope when necessary and grow chilli for paste (compare with Graham and Ochieng 2008). Although the farmer noted the barrier may be less useful in periods of frequent or heavy rain because this would remove the chilli too often or weaken the sisal, he acknowledged such rain usually only occurred early in each season before crops were foraged on regularly (Hill and Wallace 2012). 
A farmer growing jatropha as a barrier stated he intended to extend the fence around his farm because it was effective, required very little maintenance, and was cost free. The fence was not damaged by animals, did not use materials needing regular replacement and required infrequent pruning to maintain density. Another farmer identified two potential shortcomings of growing ocimum as a deterrent. Firstly, because plants have a relatively short lifespan of three to four years it is necessary to supplement the hedge with new plants every few years, and therefore he would need to set aside land for seed beds and spend time growing seedlings. Secondly, over time an ocimum hedge could occupy two or more metres of land at the farm edge, rendering that area unavailable for growing staple crops. However, the farmer added that ocimum could also be a viable cash crop if local or regional marketing networks were created and used (see Barbier 1987; Bigagambah 1996; Padulosi, Eyzaquirre and Hodgkin 1999). A farmer testing a single-row ocimum hedge noted that it occupied very little land and considered this to be a key benefit, particularly as ocimum retained animal-repellent properties while planted in one row; although the fence was difficult for baboons and (other) monkeys to jump or climb over, its efficacy was also tied to the odour of the ocimum and presence of bees. The farmer also agreed ocimum was potentially valuable as a cash crop, but noted it would be important to have a large group of farmers or a commercial organization promoting it.

It is recommended elsewhere that neighbouring farmers should assist each other to chase cropforaging wildlife from their farms (see Hill, Osborn and Plumptre 2002), and guarding could be most effective and cost efficient when conducted cooperatively over several farms or shared with a neighbour (Maples et al. 1976; Warren, Buba and Ross 2007). However, only two farmers in our study stated they shared or would consider sharing their resources to protect crops, even though there were a number of observations of farmers assisting neighbours to chase animals from their farm. Some farmers viewed other people as lazy or careless about crop protection and not using an equal or appropriate amount of effort when guarding the crops of others; they therefore considered it preferable for farmers to focus on protecting their own crops, which typically leaves little time to assist others (H. Biroch pers. comm.). 
Deterrent effectiveness was often greater when used in combination, such as ocimum with a mesh fence, jatropha with strands of barbed wire, alarm systems with rapid responses to animals entering crop fields, and barriers patrolled by guards. Most deterrents require association with guarding and responses by farmers to maintain efficacy over time; otherwise raiders will perceive deterrents to rarely carry aversive consequences. Barbed-wire fences deterred primates most when linked with farmers' responses (such as chasing or throwing objects), demonstrating that active protection is preferable to a passive barrier, as also noted by others (Osborn and Parker 2002b; Sitati and Walpole 2006). While combining techniques might be a practical way to maintain deterrent novelty and minimize habituation, it will be prudent to consider costs to farmers. For example, wire fences are sizeable investments, and it will be important to determine whether such fences add protective value to vegetation barriers that are readily grown and maintained at low cost. Similarly, guarding may involve opportunity and social costs for farmers, and should be balanced with deterrent return.

\section{Reflecting on the Importance of Engaging with Local Priorities, Perceptions and Realities}

Interviews and focus groups with farmers complemented systematic observations of wildlife and farmer behaviour to develop locally appropriate and affordable deterrents to raiding. Drawing upon baseline data from an entire growing season, it was possible to evaluate the efficacy of a range of crop-protection techniques, under almost experimental conditions, over the subsequent season. As demonstrated here, farmer-reported records provide useful information about wildlife crop-foraging activity, complement data from systematic observations by researchers and are sufficiently reliable for analysis when potential limitations are acknowledged. Most importantly, the farmers' role in data collection promoted their ownership and involvement in the project, and their commitment to participatory solutions. The observation that farmers were most interested in recalling crop foraging events by wildlife rather than domestic farm animals probably reflects commonly reported differences in how these groups of animals may be viewed. Farmers frequently tolerate even relatively high levels of crop damage by farm animals 
because they are financial assets and/or potential sources of food, and farmers often have protocols for compensating each other if their animals damage crops (Naughton-Treves 1998; Hill 2004).

Local people commented that research studies, development projects or tourism ventures were often conducted within the area, without seeking their views and involvement, or providing community benefits (also see Lauridsen 1999). Not all local people are aggrieved in these ways and many have positive perceptions of 'outsiders'; however, discussions in villages confirmed that a large number of people may take advantage of the naiveté and resources of outsiders if they perceive this to be possible. This can bias the verbal information collected in field studies (Brislin, Lonner and Thorndike 1973; Bernard 2002), and highlights the importance of understanding local context as well as building trust, communication and local participation into project planning.

Because the deterrents were developed in partnership with farmers, they were deemed locally appropriate and acceptable, even if unusual in the study area: for example, solar lights. While similar research has noted that farmers often fail to suggest crop-protection methods or appear disinterested and dependent on ideas from others (see Hill, Osborne and Plumptre 2002; Warren 2003; Webber 2006), this was not found in the present study. Farmers were enthusiastic and actively involved in assessing deterrents, often exchanging 'progress reports' about their deterrents' utility. Other local farmers did not ostracise study farmers for having fully-funded deterrents at their farms, which is not always the case (see Hill, Osborn and Plumptre 2002). Rather, other villagers supported the project because they envisaged benefits for many farmers over time (M. Diedonne, A.H. Fani, S. Oliki, and M. Kakole pers. comm.). A training and feedback workshop was conducted with all study farmers and village chairpersons at the end of Year Two to ensure effective dissemination of project results and information about how to install the deterrents. Farmers were encouraged to visit study farms to observe the range of deterrents used; study farmers also confirmed they would share deterrent information within their village. It is believed this participatory and cooperative approach was central to farmers' positive perceptions of deterrents (see Osborn 2002; Osborn and Hill 2005; Sitati, Walpole and Leader-Williams 2005; Sitati and Walpole 
2006). Although demonstrating deterrent effectiveness does not necessarily ensure use by farmers (Sitati and Walpole 2006; Graham and Ochieng 2008), positive perceptions increased the likelihood that farmers would maintain and adapt the deterrents, and continue to view them favourably (Hsiao 2008; Hsiao et al. 2013).

Primates probably adjust their crop-foraging behaviour to avoid detection by farmers and bypass alarm systems, and are unlikely to be deterred easily if crops benefit them. Consequently, any techniques used to improve farmers' detection of crop foraging will require adjustment over time to remain effective. The influence of specific sets of factors on detection might also be dynamic, changing as farmers and primates extend their experience of crop-foraging. There is no reason to presume that factors influencing animal crop damage at a farm today will always do so, or will to the same degree. Accordingly, cropprotection methods must be modifiable for changes in conditions as well as adaptation by wildlife or farmers.

\section{Conclusion}

The study not only demonstrates that it is possible to develop, implement and monitor a range of effective deterrents to reduce crop-foraging, but also confirms the importance of doing this in partnership with farmers. Participatory projects often build relationships between stakeholders, improve communication, promote better understanding of alternative perspectives and reduce conflict and misunderstandings (Newmark et al. 1993; Hulme and Murphree 2001; Madden 2004). However, while learning and working together with farmers may be beneficial in itself, ineffective or misguided interventions that waste time and resources can undermine interest in mitigation goals (see Stewart, Coles and Pullin 2005). Deterrents should also not be viewed as an entire or 'set and forget' solution to crop damage issues; they may simply address symptoms rather than causes (Barnes 2002). The greater the extent to which intervention strategies (1) are based on a thorough and accurate account of crop foraging activity, (2) incorporate an understanding of crop-foraging animal and farmer behaviour, and (3) involve farmers and acknowledge 
their interests and perceptions, the greater the probability of those strategies being effective. Before implementing an intervention to protect crops it is imperative to understand the context of crop damage by wildlife. Because human dimensions are central to this context, it is critical to work alongside stakeholders as partners when developing and implementing intervention plans.

\section{Acknowledgements}

For permissions to conduct the research we thank the Uganda National Council for Science and Technology, Uganda Wildlife Authority, and National Forestry Authority, Uganda. Financial support was provided by The Leverhulme Trust, American Society of Primatologists, North of England Zoological Society, Rufford Small Grants, Parkes Foundation, and Primate Society of Great Britain. Mawa Diedonne, Andama Hanington Fani, Amandu Geoffrey, Johnson Ayebale, Helen Biroch, Alfred Awio, Phillip Madrira, Enzama Anthony, Rob Bacon, Tim Pearson, and Andrea Wallace provided invaluable field assistance. We especially thank the farmers, families, and village chairpersons of Nyabyeya Parish for their key involvement, support, enthusiasm, and hospitality throughout the research.

Catherine Hill is Professor of Anthropology in the Department of Social Sciences at Oxford Brookes University. Her research focuses on people-wildlife relationships, conservation conflicts and implications for people's perceptions of wildlife, biodiversity conservation and local communities.

Graham Wallace obtained a PhD at Oxford Brookes University and an MBA through Durham University Business School. With a focus on applied research, his interests include wildlife ecology, interactions between wildlife and humans, behavioural economics in conservation, anthropogenic impacts on ecosystems and implications for management strategy. Graham has extensive experience working with 
rural communities in sub-Saharan Africa, and is currently engaged in coastal marine ecology research in British Columbia, Canada.

\section{References}

Abbot, J.I.O., et al. 2001. 'Understanding the Links between Conservation and Development in the Bamenda Highlands, Cameroon', World Development 29(7): 1115-36.

Adams, W.M. 1998. 'Conservation and Development', in W.J. Sutherland (ed.), Conservation Science and Action. Oxford: Blackwell Science, pp. 286-315.

Altrichter, M. 2006. 'Wildlife in the Life of Local People of the Semi-Arid Argentine Chaco', Biodiversity and Conservation 15(8): 2719-2736.

Armitage, D.R. 2003. 'Traditional Agroecological Knowledge, Adaptive Management and the Sociopolitics of Conservation in Central Sulawesi, Indonesia', Environmental Conservation 30(1): 7990.

Baker, J., et al. 2013. 'Linking Protected Area Conservation with Poverty Alleviation in Uganda: Integrated Conservation and Development at Bwindi Impenetrable National Park', in J.B. Smith (ed.), National Parks. New York: Nova Science Publishers, pp. 47-103.

Barbier, E.B. 1987. Cash Crops, Food Crops and Agricultural Sustainability. Gatekeeper Series No. 2: International Institute for Environment and Development, Sustainable Agriculture and Rural Livelihoods Programme.

Barnes, R.F.W. 1996. 'The Conflict between Humans and Elephants in the Central African Forests', Mammal Review 26(2/3): 67-80.

Barnes, R.F.W. 2002. 'Treating Crop-Raiding Elephants with Aspirin', Pachyderm 33: 96-99. 
Beale, C.M., and P. Monaghan. 2004. 'Behavioural Responses to Human Disturbance: A Matter of Choice?' Animal Behaviour 68(5): 1065-1069.

Bernard, H.R. 2002. Research Methods in Anthropology: Qualitative and Quantitative Methods, 3rd ed. Walnut Creek, CA: AltaMira Press.

Bigagambah, J.R. 1996. Marketing of Smallholder Crops in Uganda. Kampala, Uganda: Fountain Publishers.

Blomley, T. 2000. Woodlots, Woodfuel and Wildlife: Lessons from Queen Elizabeth National Park, Uganda. Gatekeeper Series No. 90: International Institute for Environment and Development, Sustainable Agriculture and Rural Livelihoods Programme.

Boydston, E.E., et al. 2003. 'Altered Behaviour in Spotted Hyenas Associated with Increased Human Activity', Animal Conservation 6: 207-219.

Brislin, R.W., W.J. Lonner and R.M. Thorndike. 1973. Cross-Cultural Research Methods. New York: Wiley.

Buchanan, D.A., and A.A. Huczynski. 2010. Organizational Behaviour, 7th ed. Harlow: Pearson Education.

Bulte, E.H., and D.Rondeau . 2005. 'Why Compensating Wildlife Damages may be Bad for Conservation', Journal of Wildlife Management 69(1): 14-19.

Bush, G., et al. 2004. 'The Value of Uganda's Forests: A Livelihoods and Ecosystems Approach', WCS Albertine Rift Programme, EU Forest Resources Management and Conservation Programme, National Forest Authority, pp. 101. 
CARE et al. 2003. 'Reducing the Costs of Conservation to Frontline Communities in Southwest Uganda. Knowledge Base Review Report', CARE International in Uganda, Institute of Tropical Forest Conservation, Conservation Development Centre, and Wildlife Conservation Society.

Chase, L.C., D.J. Decker and T.B. Lauber. 2004. 'Public Participation in Wildlife Management: What do Stakeholders Want', Society and Natural Resources 17(7): 629-639.

Chiyo, P.I., et al. 2005. 'Temporal Patterns of Crop Raiding by Elephants: A Response to Changes in Forage Quality or Crop Availability?‘ African Journal of Ecology 43(1): 48-55.

Choudhury, A. 2004. 'Human-Elephant Conflicts in Northeast India', Human Dimensions of Wildlife 9(4): $261-270$.

Colfer, C.J.P., R.L. Wadley and P. Venkateswarlu. 1999. 'Understanding Local People's Use of Time: A Pre-condition for Good Co-management', Environmental Conservation 26(1): 41-52.

Conover, M. 2002. Resolving Human-Wildlife Conflicts: The Science of Wildlife Damage Management. Boca Raton, FL: Lewis Publishers.

Dickman, A.J. 2010. 'Complexities of Conflict: The Importance of Considering Social Factors for Effectively Resolving Human-Wildlife Conflict', Animal Conservation 13(5): 458-466.

Esterberg, K.G. 2002. Qualitative Methods in Social Research. Boston, MA: McGraw Hill.

Forthman, D.L., S.C. Strum and G.M. Muchemi. 2005. 'Applied Conditioned Taste Aversion and the Management and Conservation of Crop-Raiding Primates', in J. D. Paterson and J. Wallis (eds), Commensalism and Conflict: The Human-Primate Interface. Norman, OK: American Society of Primatologists, pp. $420-443$.

Fuentes, A., M. Southern and K.G. Suaryana. 2005. 'Monkey Forests and Human Landscapes: Is Extensive Sympatry Sustainable for Homo sapiens and Macaca fascicularis on Bali?' in J.D. 
Paterson and J. Wallis (eds), Commensalism and Conflict: The Human-Primate Interface. Norman, OK: American Society of Primatologists, pp. 168-195.

Gillingham, S., and P.C. Lee. 1999. 'The Impact of Wildlife-Related Benefits on the Conservation Attitudes of Local People around the Selous Game Reserve, Tanzania', Environmental Conservation 26(3): 218-228.

_ 2003. 'People and Protected Areas: A Study of Local Perceptions of Wildlife Crop-Damage Conflict in an Area Bordering the Selous Game Reserve, Tanzania', Oryx 37(3): 316-325.

Graham, M.D., and T. Ochieng. 2008. 'Uptake and Performance of Farm-Based Measures for Reducing Crop Raiding by Elephants Loxodonta africana among Smallholder Farms in Laikipia District, Kenya', Oryx 42(1): 76-82.

Hackel, J.D. 1999. 'Community Conservation and the Future of Africa's Wildlife', Conservation Biology 13(4): 726-734.

Hansen, L.K. 2003. 'Influence of Forest-Farm Boundaries and Human Activity on Raiding by the Buton macaque (Macaca ochreata brunnescens).' MSc dissertation, Oxford Brookes University, Oxford, pp. 46.

Happold, D.C.D. 1995. 'The Interactions between Humans and Mammals in Africa in Relation to Conservation: A Review', Biodiversity and Conservation 4(4): 395-414.

Heong, K.L., and M.M. Escalada. 1998. 'Changing Rice Farmers' Pest Management Practices through Participation in a Small-Scale Experiment', International Journal of Pest Management 44(4): 191-97.

Hill, C.M. 1997. 'Crop-Raiding by Wild Vertebrates: The Farmer's Perspective in an Agricultural Community in Western Uganda', International Journal of Pest Management 43(1): 77-84. 
- 2000. 'Conflict of Interest between People and Baboons: Crop Raiding in Uganda', International Journal of Primatology 21(2): 299-315.

- 2002a. 'People, Crops and Wildlife: A Conflict of Interests', in C.M Hill, F.V. Osborn and A.J. Plumptre (eds), Human-Wildlife Conflict: Identifying the Problem and Possible Solutions. Albertine Rift Technical Report Series No. 1: Wildlife Conservation Society, pp. 61-68. - 2002b. 'Primate Conservation and Local Communities - Ethical Issues and Debates', American Anthropologist 104(4): 1184-1194.

_ 2004. 'Farmers' Perspectives of Conflict at the Wildlife-Agriculture Boundary: Some Lessons Learned from African Subsistence Farmers', Human Dimensions of Wildlife 9(4): 279-286. 2005. 'People, Crops, and Primates: A Conflict of Interests', in J. D. Paterson and J. Wallis (eds), Commensalism and Conflict: The Human-Primate Interface. Norman, OK: American Society of Primatologists, pp. 40-59.

- 2015. 'Perspectives of “Conflict” at the Wildlife-Agriculture Boundary: 10 Years On', Human Dimensions of Wildlife 20(4): 296-301.

Hill, C.M., F.V. Osborn and A.J. Plumptre. 2002. 'Human-Wildlife Conflict: Identifying the Problem and Possible Solutions'. Albertine Rift Technical Report Series No. 1: Wildlife Conservation Society. Hill, C.M., and G.E. Wallace. 2012. 'Crop Protection and Conflict Mitigation: Reducing the Costs of Living alongside Non-Human Primates', Biodiversity and Conservation 21(10): 2569-2587.

Hoare, R.E. 1995. 'Options for the Control of Elephants in Conflict with People', Pachyderm 19: 54-63.

Horrocks, J.A., and J Baulu. 1988. 'Effects of Trapping on the Vervet (Cercopithecus aethiops sabaeus) Population in Barbados', American Journal of Primatology 15: 223-233. 
Hsiao, S.S., et al. 2013. 'Crop-Raiding Deterrents around Budongo Forest Reserve: An Evaluation through Farmer Actions and Perceptions', Oryx 47(4): 569-577.

Hulme, D., and M.W. Murphree (eds). 2001. African Wildlife and Livelihoods: The Promise and Performance of Community Conservation. Oxford: James Curry.

Hutton, J.M., and N. Leader-Williams. 2003. 'Sustainable Use and Incentive-driven Conservation: Realigning Human and Conservation Interests', Oryx 37(2): 215-226.

Hygnstrom, S.E., R.M. Timm and G.E. Larson (eds). 1994. Prevention and Control of Wildlife Damage. Washington, DC: Natural Resources and Rural Development Unit, US Department of Agriculture.

Infield, M. 1988. 'Attitudes of a Rural Community towards Conservation and a Local Conservation Area in Natal, South Africa', Biological Conservation 45(1): 21-46.

Kagiri, J. 2002. 'Human-Wildlife Conflicts in Kenya: A Conflict Resolution Concept', in C.M. Hill, F.V. Osborn and A.J. Plumptre (eds), Human-Wildlife Conflict: Identifying the Problem and Possible Solutions. Albertine Rift Technical Report Series No. 1: Wildlife Conservation Society, pp. 4447.

Kapila, S., and F. Lyon. 1994. Expedition Field Techniques: People Oriented Research. London: Expedition Advisory Centre, Royal Geographical Society.

Kepe, T., B. Cousins and S. Turner. 2001. 'Resource Tenure and Power Relations in Community Wildlife: The Case of Mkambati Area, South Africa', Society and Natural Resources 14(10): $911-925$.

Knickerbocker, T.J., and J. Waithaka. 2005. 'People and Elephants in the Shimba Hills, Kenya', in R. Woodroffe, S. Thirgood and A. Rabinowitz (eds), People and Wildlife: Conflict or Coexistence? Cambridge: Cambridge University Press, pp. 224-238. 
Lane, S.J., and H. Higuchi. 1998. 'Efficacy of Common Protection Devices in Preventing Night-Time Damage of Cabbage Crops by Spot-Billed Ducks in Japan', International Journal of Pest Management 44(1): 29-34.

Lauridsen, M. 1999. 'Workers in a Forest: Understanding the Complexity of Incorporating Local People in Modern Management. A Case Study of the Nyabyeya Parish in Western Uganda', MSc thesis, University of Copenhagen.

Lee, P.C., and N.E.C. Priston. 2005. 'Human Attitudes to Primates: Perceptions of Pests, Conflict and Consequences for Primate Conservation', in J.D. Paterson and J. Wallis (eds), Commensalism and Conflict: The Human-Primate Interface. Norman, OK: American Society of Primatologists, pp. $1-23$.

MacKenzie, C.A., and P. Ahabyona. 2012. 'Elephants in the Garden: Financial and Social Costs of Crop Raiding', Ecological Economics 75(1): 72-82.

Madden, F. 2004. 'Creating Coexistence between Humans and Wildlife: Global Perspectives on Local Efforts to Address Human-Wildlife Conflict', Human Dimensions of Wildlife 9(4): 247-257.

Maples, W.R., et al. 1976. 'Adaptations of Crop-Raiding Baboons in Kenya', American Journal of Physical Anthropology 45(2): 309-315.

Messmer, T.A. 2000. 'The Emergence of Human-Wildlife Conflict Management: Turning Challenges into Opportunities', International Biodeterioration \& Biodegradation 45(3-4): 97-102.

Miller, K.K., and T.K. McGee. 2001. 'Toward Incorporating Human Dimensions Information into Wildlife Management Decision-Making, Human Dimensions of Wildlife 6(3): 205-221.

Morton-Williams, J. 1993. Interviewer Approaches. Aldershot: Dartmouth Publishing Company. 
Mukherjee, A., and C.K. Borad. 2004. 'Integrated Approach towards Conservation of Gir National Park: The Last Refuge of Asiatic lions, India', Biodiversity and Conservation 13: 2165-2182.

Naughton-Treves, L. 1997. 'Farming the Forest Edge: Vulnerable Places and People around Kibale National Park, Uganda', Geographical Review 87(1): 27-46.

—. 1998. 'Predicting Patterns of Crop Damage by Wildlife around Kibale National Park, Uganda', Conservation Biology 12(1): 156-168.

- 2001. 'Farmers, Wildlife, and the Forest Fringe', in W. Weber et al. (eds), African Rain Forest Ecology and Conservation. New Haven, CT: Yale University Press, pp. 588.

Newmark, W.D., et al. 1993. 'Conservation Attitudes of Local People Living Adjacent to Five Protected Areas in Tanzania', Biological Conservation 63(2): 177-183.

Nyhus, P.J., R. Tilson and Sumianto. 2000. 'Crop-Raiding Elephants and Conservation Implications at Way Kambas National Park, Sumatra, Indonesia', Oryx 34(4): 262-274.

O’Connell-Rodwell, C.E., et al. 2000. 'Living with the Modern Conservation Paradigm: Can Agricultural Communities Co-exist with Elephants? A Five-year Case Study in East Caprivi, Namibia', Biological Conservation 93(3): 381-391.

Osborn, F.V. 2002. 'Capsicum oleoresin as an Elephant Repellent: Field Trials in the Communal Lands of Zimbabwe', Journal of Wildlife Management 66(3): 674-677.

Osborn, F.V., and C.M. Hill. 2005. 'Techniques to Reduce Crop Loss: Human and Technical Dimensions in Africa', in R. Woodroffe, S. Thirgood and A. Rabinowitz (eds), People and Wildlife: Conflict or Coexistence? Cambridge: Cambridge University Press, pp. 72-85. 
Osborn, F.V., and G.E. Parker. 2002a. 'Living with Elephants II: A Manual for Implementing an Integrated Programme to Reduce Crop Loss to Elephants and to Improve Livelihood Security of Small-Scale Farmers', Mid Zambezi Elephant Project, pp. 21.

2002b. 'An Integrated Approach toward Problem Animal Management', in C.M. Hill, F.V.

Osborn and A.J. Plumptre (eds), Human-Wildlife Conflict: Identifying the Problem and Possible Solutions. Albertine Rift Technical Report Series No. 1: Wildlife Conservation Society, pp. 121127.

. 2003. 'Towards an Integrated Approach for Reducing the Conflict between Elephants and People: A Review of Current Research', Oryx 37(1): 80-84.

Padulosi, S., P. Eyzaquirre and T. Hodgkin. 1999. 'Challenges and Strategies in Promoting Conservation and Use of Neglected and Underutilized Crop Species', in J. Janick (ed.), Perspectives on New Crops and New Uses. Alexandria, VA: ASHS Press, pp. 140-149.

Paterson, J.D., and J. Wallis (eds). 2005. Commensalism and Conflict: The Human-Primate Interface. Norman, OK: American Society of Primatologists.

Peterson, M.N., et al. 2010. 'Rearticulating the Myth of Human-Wildlife Conflict', Conservation Letters 3(2): 74-82.

Pirta, R.S., M. Gadgil and A.V. Kharshikar. 1997. 'Management of the Rhesus Monkey Macaca mulatta and Hanuman Langur Presbytis entellus in Himachal Pradesh, India', Biological Conservation 79(1): 97-106.

Plumptre, A.J. 2002. 'Crop Raiding around the Parc National des Volcans, Rwanda: Farmer's Attitudes and Possible Links with Poaching,, in C.M. Hill, F.V. Osborn and A.J. Plumptre (eds), HumanWildlife Conflict: Identifying the Problem and Possible Solutions. Albertine Rift Technical Report Series No. 1: Wildlife Conservation Society, pp. 79-88. 
Plumptre, A.J., et el. 2004. 'The Socio-economic Status of People Living Near Protected Areas in the Central Albertine Rift.’ Albertine Rift Technical Report Series No. 4: Wildlife Conservation Society, pp. 132.

Plumptre, A.J., and V. Reynolds. 1994. 'The Effect of Selective Logging on the Primate Populations in the Budongo Forest Reserve, Uganda', Journal of Applied Ecology 31(4): 631-641.

Priston, N.E.C., and M.R. McLennan. 2013. 'Managing Humans, Managing Macaques: Human-Macaque Conflict in Asia and Africa', in S. Radhakrishna, M. Huffman and A. Sinha (eds), The Macaque Connection: Cooperation and Conflict between Humans and Macaques. New York: Springer, pp. $225-250$.

Randall, S., and T. Koppenhaver. 2004. 'Qualitative Data in Demography: The Sound of Silence and Other Problems', Demographic Research 11(3): 57-94.

Rao, M., and P.J.K. McGowan. 2002. 'Wild-Meat Use, Food Security, Livelihoods, and Conservation', Conservation Biology 16(3): 580-583.

Redpath, S.M., et al. 2013. 'Understanding and Managing Conservation Conflicts', Trends in Ecology and Evolution 28(2): 100-109.

Riley, S.J., et al. 2003. 'Adaptive Impact Management: An Integrative Approach to Wildlife Management', Human Dimensions of Wildlife 8(2): 81-95.

Rode, K.D., et al. 2006. 'Nutritional Ecology of Elephants in Kibale National Park, Uganda, and its Relationship with Crop-Raiding Behaviour', Journal of Tropical Ecology 22: 441-449.

Rollins, K., and H.C. Briggs. 1996. 'Moral Hazard, Externalities, and Compensation for Crop Damages from Wildlife', Journal of Environmental Economics and Management 31(3): 368-386. 
Rollinson, D. 2005. Organisational Behaviour and Analysis: An Integrated Approach, 3rd ed. Harlow: Prentice Hall.

Sitati, N.W., and M.J. Walpole. 2006. 'Assessing Farm-Based Measures for Mitigating Human-Elephant Conflict in Transmara District, Kenya', Oryx 40(3): 279-286.

Sitati, N.W., M.J. Walpole and N. Leader-Williams. 2005. 'Factors Affecting Susceptibility of Farms to Crop Raiding by African Elephants: Using a Predictive Model to Mitigate Conflict', Journal of Applied Ecology 42: 1175-1182.

Soto, B., S.M. Munthali and C. Breen. 2001. 'Perceptions of the Forestry and Wildlife Policy by the Local Communities Living in the Maputo Elephant Reserve, Mozambique', Biodiversity and Conservation 10: 1723-1738.

Stewart, G.B., C.F. Coles and A.S. Pullin. 2005. 'Applying Evidence-Based Practice in Conservation Management: Lessons from the First Systematic Review and Dissemination Projects', Biological Conservation 126(2): 270-278.

Strum, S.C. 1986. 'Activist Conservation: The Human Factor in Primate Conservation in Source Countries', in J.G. Else and P.C. Lee (eds), Primate Ecology and Conservation. Cambridge: Cambridge University Press, pp. 367-382.

1994. 'Prospects for Management of Primate Pests', Revue d'Ecologie (La Terre Et La Vie) 49(3): 295-306.

Thirgood, S., R. Woodroffe and A. Rabinowitz. 2005. 'The Impact of Human-Wildlife Conflict on Human Lives and Livelihoods', in R. Woodroffe, S. Thirgood and A. Rabinowitz (eds), People and Wildlife: Conflict or Coexistence? Cambridge: Cambridge University Press, pp. 13-26.

Toutain, B., M.-N. De Visscher and D. Dulieu. 2004. 'Pastoralism and Protected Areas: Lessons Learned from Western Africa', Human Dimensions of Wildlife 9(4): 287-295. 
Tungittiplakorn, W., and P. Dearden. 2002. 'Biodiversity Conservation and Cash Crop Development in Northern Thailand', Biodiversity and Conservation 11(11): 2007-2025.

Tweheyo, M., C.M. Hill and J. Obua. 2005. 'Patterns of Crop Raiding by Primates around the Budongo Forest Reserve, Uganda', Wildlife Biology 11(3): 237-247.

Van Huis, A., and F. Meerman. 1997. 'Can we Make IPM Work for Resource-Poor Farmers in SubSaharan Africa?' International Journal of Pest Management 43(4): 313-320.

Wallace, G.E. 2010. 'Monkeys in Maize: Primate Crop-Raiding Behaviour and Developing On-farm Techniques to Mitigate Human-Wildlife Conflict', $\mathrm{PhD}$ thesis, Oxford Brookes University, Oxford, pp. 528.

Wallace, G.E., and C.M. Hill. 2012. 'Crop Damage by Primates: Quantifying the Key Parameters of Crop-Raiding Events', PLoS ONE 7(10): e46636.

Warren, Y. 2003. 'Olive Baboons (Papio cynocephalus anubis): Behaviour, Ecology and Human Conflict in Gashaka Gumti National Park, Nigeria', PhD thesis, University of Surrey, Roehampton, pp. 308.

Warren, Y., B. Buba and C. Ross. 2007. 'Patterns of Crop-Raiding by Wild and Domestic Animals near Gashaka Gumti National Park, Nigeria', International Journal of Pest Management 53(3): 207216.

Webber, A.D. 2006. 'Primate Crop Raiding in Uganda: Actual and Perceived Risks around Budongo Forest Reserve', PhD thesis, Oxford Brookes University, Oxford.

Webber, A.D., and C.M. Hill. 2014. 'Using Participatory Risk Mapping (PRM) to Identify and Understand People's Perceptions of Crop Loss to Animals in Uganda', PLoS ONE 9(7): e102912. 
Webber, A.D., C.M. Hill and V. Reynolds. 2007. 'Assessing the Failure of a Community-Based HumanWildlife Conflict Mitigation Project in Budongo Forest Reserve, Uganda', Oryx 41(2): 177-184.

Woodroffe, R., S. Thirgood and A. Rabinowitz (eds). 2005. People and Wildlife: Conflict or Coexistence? Cambridge: Cambridge University Press.

WWF. 2005. Human Wildlife Conflict Manual. Harare: World Wide Fund for Nature, Southern Africa Regional Programme.

Young, J., et al. 2005. 'Towards Sustainable Land Use: Identifying and Managing the Conflicts between Human Activities and Biodiversity Conservation in Europe', Biodiversity and Conservation 14(7): 1641-1661.

\section{Notes}

1. Vertebrate species reported to consume crops and other human foods are listed in Hygnstrom, Timm and Larson (1994), Naughton-Treves (1997: 32), Conover (2002), CARE et al. (2003), Warren (2003: 4, 8), Lee and Priston (2005: 4-8), Hill (2005: 43), Webber (2006: 9-10, 13-15) and Priston and McLennan (2013).

2. The term 'deterrent' refers here to any technique intended to protect crops from damage by animals and can be a sensory stimulus, structure, tool, action or procedure. The term therefore encompasses the broad general range of alarms, repellents, barriers, alternate crop locations and synchronised planting, as well as traditional forms such as guarding, fires or scarecrows (Hill, Osborn and Plumptre 2002; CARE et al. 2003; Lee and Priston 2005; Osborn and Hill 2005; Sitati and Walpole 2006).

3. Here we retain the term CRE (crop-raiding event) used in earlier publications to facilitate comparison; however, we recommend this term be revised to 'crop-foraging event' in future publications.

4. This would mainly comprise lack of vigilance and/or not being ready to respond to wildlife incursions. 